\title{
Comparative Interactions of Anesthetic Alkylphenols with Lipid Membranes
}

\author{
Hironori Tsuchiya ${ }^{*}$, Maki Mizogami² \\ ${ }^{1}$ Department of Dental Basic Education, School of Dentistry, Asahi University, Mizuho, Japan \\ ${ }^{2}$ Department of Anesthesiology and Reanimatology, Faculty of Medical Sciences, University of Fukui, \\ Eiheiji-cho, Japan \\ Email: ${ }^{\text {hiro@dent.asahi-u.ac.jp }}$
}

Received 30 October 2014; revised 30 November 2014; accepted 19 December 2014

Copyright (C) 2014 by authors and Scientific Research Publishing Inc.

This work is licensed under the Creative Commons Attribution International License (CC BY).

http://creativecommons.org/licenses/by/4.0/

(c) (i) Open Access

\begin{abstract}
Objective: While substituted phenols have a variety of pharmacological activity, the mechanism underlying their anesthetic effects remains uncertain especially about the critical target. We characterized the lipid membrane-interacting properties of different phenols by comparing with general anesthetic propofol and local anesthetics. Based on the results, we also studied the pharmacological effects possibly associated with their membrane interactivities. Methods: 1,6-Diphenyl-1,3,5-hexatriene-labeled lipid bilayer membranes were prepared with 1,2-dipalmitoylphosphatidylcholine as model membranes and with different phospholipids and cholesterol to mimic neuronal membranes. These membrane preparations were treated with phenols and anesthetics at 1 - $200 \mu \mathrm{M}$, followed by measuring the fluorescence polarization to determine the membrane interactivities to change membrane fluidity. Antioxidant effects were fluorometrically determined using diphenyl-1-pyrenylphosphine-incorporated liposomes which were treated with 10 - $100 \mu M$ phenols, and then peroxidized with $10 \mu M$ peroxynitrite. Results: Several phenols interacted with the model membranes and the neuronal mimetic membranes to increase their fluidity at 1 - $10 \mu \mathrm{M}$ as well as lidocaine and bupivacaine did at $50-200 \mu \mathrm{M}$. Their comparative potencies were propofol $>$ thymol $>$ isothymol $>$ guaiacol $>$ phenol $>$ eugenol, and bupivacaine $>$ lidocaine, consistent with the rank order of neuro-activity. These phenols inhibited membrane lipid peroxidation at 10 and $100 \mu \mathrm{M}$ with the potencies correlating to their membrane interactivities. Conclusion: The structure-specific membrane interaction is at least in part responsible for the pharmacology of anesthetic alkylphenols. Membrane-interacting antioxidant alkylphenols may be protective against the peroxynitrite-relating ischemia/reperfusion injury.
\end{abstract}

\section{Keywords}

Alkylphenol, Anesthetic Mechanism, Lipid Membrane, Interaction, Antioxidant

\footnotetext{
${ }^{*}$ Corresponding author.
} 


\section{Introduction}

Since phenol was introduced as a surgical disinfectant in the 1860s, substituted phenols or phenol derivatives have been applied as antiseptic, antibacterial, analgesic and anti-inflammatory agents. In addition, many of them possess the local anesthetic activity, making them very useful in dentistry when the relevant pain is associated with infection and inflammation. Phenolic agents are extensively used to allay the pain of dental pulps or sedate the inflamed pulps and to disinfect root canals and dentins. Orally and intravenously administered phenols are also effective for inflammatory and peripheral/central nervous pains [1] [2]. In the anesthesiology field, propofol is certainly best known of medicinal phenols. Intravenous anesthetic propofol has been widely used to induce and maintain general anesthesia, as a part of total intravenous anesthesia and for procedural sedation. The other alkylphenols also show the neuro-activity through the affinity for $\mathrm{GABA}_{\mathrm{A}}$ receptors similarly to propofol [3] [4].

As suggested by Haeseler and Leuwer [5], a benzene ring with some substituents is the structural characteristics for pharmacologically active agents such as pulp-sedative thymol, eugenol and guaiacol, general anesthetic propofol and local anesthetic lidocaine (see Figure 1 for their structures). In addition to analgesic and anesthetic effects, alkylphenols have antimicrobial, anti-inflammatory, antithrombotic and anticancer effects [6]-[8]. However, the molecular mechanisms to explain such diversity in pharmacological activity have not necessarily been elucidated especially about the critical target.

Drugs and chemicals mechanistically act not only on receptor, channel and enzyme proteins but also on membrane lipids and their constituting lipid bilayers, thereby inhibiting or reducing bacterial growth, inflammatory reaction, platelet aggregation and tumor cell proliferation. Antimicrobial [9], non-steroidal anti-inflammatory [10], antiplatelet [11] and antiproliferative drugs [12] change the physicochemical properties such as fluidity, order and elasticity of biological and artificial lipid membranes by interacting with membrane lipids. Since antimicrobial, anti-inflammatory, antiplatelet and anticancer phenols and their structurally-relating compounds act on biomembranes [13] [14], the interactivity with lipid bilayers is presumed to be one of principal characteristics in common with phenolic agents.

Both local anesthetics and general anesthetic propofol block voltage-operated ion channels, but they differently act on $\mathrm{GABA}_{\mathrm{A}}$ receptors. Lidocaine, bupivacaine and procaine inhibit GABA-induced currents, possibly

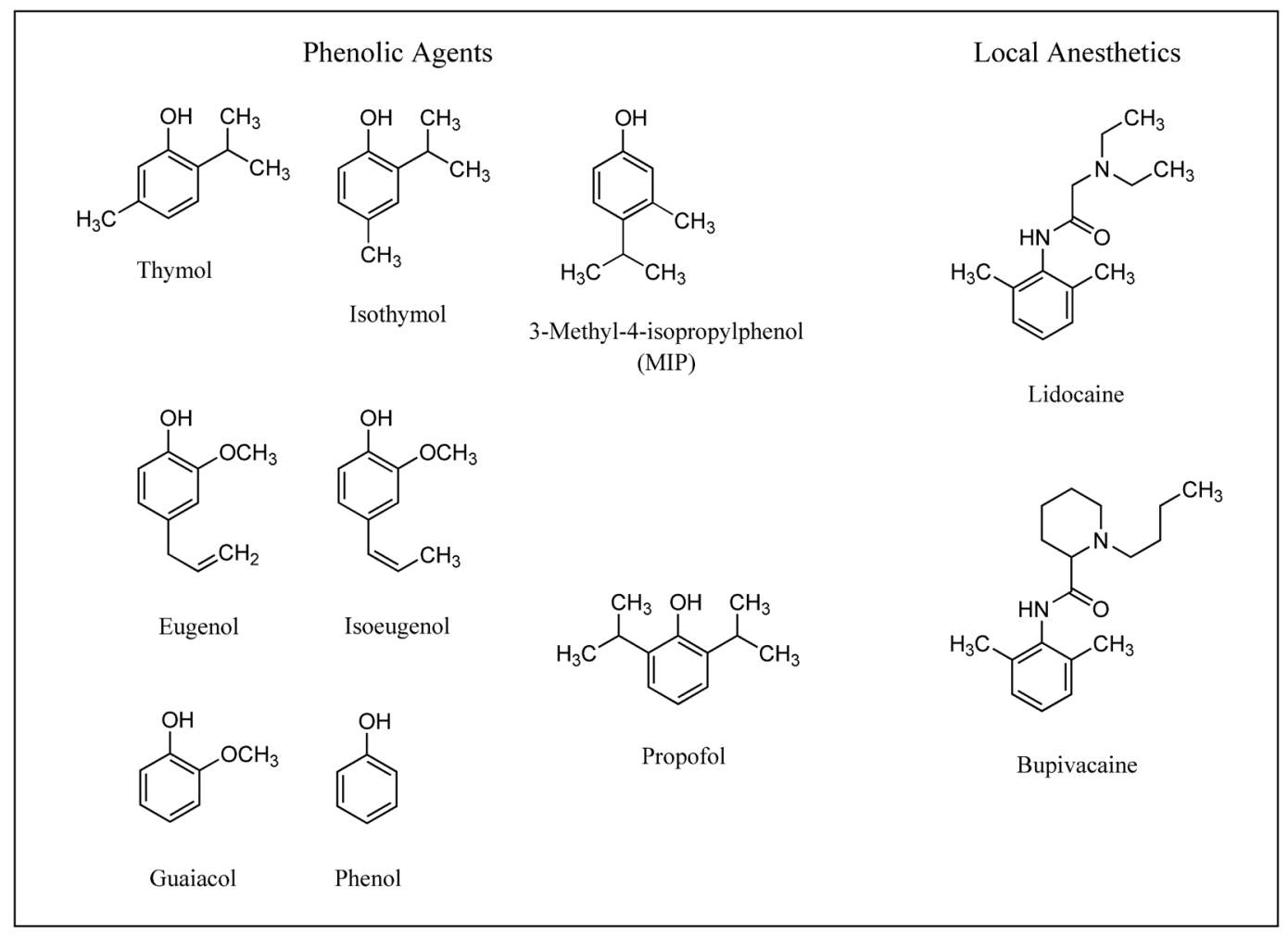

Figure 1. Phenols and anesthetics tested in this study. 
producing their CNS toxicity [15], whereas propofol potentiates GABA-evoked currents and directly activates $\mathrm{GABA}_{\mathrm{A}}$ receptors [5]. Thymol, eugenol and guaiacol share the effects on peripheral and central nerves with lidocaine and propofol, respectively. These dental phenols block voltage-operated ion channels and inhibit sodium currents as well as local anesthetics [16] [17], although they allosterically positively modulate $\mathrm{GABA}_{\mathrm{A}}$ receptors similarly to propofol [3] [4].

The physicochemical properties of lipid bilayer membranes regulate voltage-dependent sodium channel and $\mathrm{GABA}_{\mathrm{A}}$ receptor functions [18] [19]. Besides membrane-embedded channels and receptors, local and general anesthetics possibly interact with membrane lipids to modify the lipid environments surrounding functional proteins as the primary mode of action. In this study, we characterized the lipid membrane-interacting properties of structurally-different anesthetic phenols (Figure 1) by comparing with general and local anesthetics. We also studied the pharmacological effects which could be associated with their membrane interactivities.

\section{Methods}

\subsection{Chemicals}

Phenolic thymol (5-methyl-2-isopropylphenol), isothymol (4-methyl-2-isopropylphenol), 3-methyl-4-isopropylphenol (MIP), eugenol (2-methoxy-4-(2-propenyl)phenol), isoeugenol (2-methoxy-4-(1-propenyl)phenol), guaiacol (2-methoxyphenol), phenol and propofol (2,6-diisopropylphenol), local anesthetic lidocaine and bupivacaine, and antioxidant $\alpha$-tocopherol were supplied by Aldrich (Milwaukee, WI), Sigma (St. Louis, MO), Wako Pure Chemicals (Osaka, Japan) or Tokyo Chemical Industrials (Tokyo, Japan). Phospholipids: 1,2-dipalmitoylphosphatidylcholine (DPPC),1-palmitoyl-2-oleoylphosphatidylcholine (POPC), 1-palmitoyl-2-oleoylphosphatidylethanolamine (POPE), 1-palmitoyl-2-oleoylphosphatidylserine (POPS) and porcine brain sphingomyelin (SM) were purchased from Avanti Polar Lipids (Alabaster, AL), and cholesterol from Wako Pure Chemicals. 1,6-Diphenyl-1,3,5-hexatriene (DPH) was obtained from Molecular Probes (Eugene, OR), and diphenyl-1-pyrenylphosphine (DPPP) and peroxynitrite from Dojindo (Kumamoto, Japan). Dimethyl sulfoxide (DMSO) and ethanol of spectroscopic grade (Kishida; Osaka, Japan) and water of liquid chromatographic grade (Kishida) were used for preparing reagent solutions. All other chemicals were of the highest analytical grade available commercially.

\subsection{Membrane Preparation}

Lipid bilayer membranes were prepared as reported previously [20] with some modifications as follows. An aliquot $(250 \mu \mathrm{l})$ of the ethanol solution of phospholipids and cholesterol (total lipids of $10 \mathrm{mM}$ ) and DPH (50 $\mu \mathrm{M}$ ) was repeatedly injected four times into $199 \mathrm{ml}$ of $20 \mathrm{mM}$ sodium phosphate buffer (pH 7.4, containing 100 $\mathrm{mM} \mathrm{KCl)} \mathrm{under} \mathrm{stirring} \mathrm{above} \mathrm{the} \mathrm{phase} \mathrm{transition} \mathrm{temperatures} \mathrm{of} \mathrm{phospholipids} \mathrm{to} \mathrm{prepare} \mathrm{DPH-labeled} \mathrm{un-}$ ilamellar vesicles suspended in the buffer. Their lipid compositions were (1) $100 \mathrm{~mol} \%$ DPPC for DPPC model membranes which have been most frequently used for studying membrane-active drugs and (2) $36 \mathrm{~mol} \%$ POPC, $22 \mathrm{~mol} \%$ POPE, $3.5 \mathrm{~mol} \%$ POPS, $3.5 \mathrm{~mol} \% \mathrm{SM}$ and $35 \mathrm{~mol} \%$ cholesterol to mimic neuronal membranes.

\subsection{Interaction with Lipid Membranes}

The DMSO solutions of thymol, isothymol, MIP, eugenol, isoeugenol, guaiacol, phenol, propofol, lidocaine and bupivacaine were applied to the membrane preparations so that final concentrations were $1-200 \mu \mathrm{M}$. The concentration of DMSO vehicle was adjusted to be $0.5 \%(\mathrm{v} / \mathrm{v})$ of the total volume so as not to affect the fluidity of intact membranes. DMSO of the corresponding volume was added to controls. After the reaction at $37^{\circ} \mathrm{C}$ for 15 min, DPH fluorescence polarization was measured by an RF-540 spectrofluorometer (Shimadzu; Kyoto, Japan) equipped with a polarizer and a cuvette thermo-controller as reported previously [20]. Polarization values were calculated by the formula $\left(I_{\mathrm{VV}}-G I_{\mathrm{VH}}\right) /\left(I_{\mathrm{VV}}+G I_{\mathrm{VH}}\right)$, in which $I$ is the fluorescence intensity and the subscripts $\mathrm{V}$ and $\mathrm{H}$ refer to the vertical and horizontal orientation of the excitation and emission polarizer, respectively. The grating correction factor $\left(G=I_{\mathrm{HV}} / I_{\mathrm{HH}}\right)$ was used to correct the polarizing effects of a monochromator. Compared with controls, a decrease of fluorescence polarization means an increase of membrane fluidity (membrane fluidization). Because the DPH polarization values of control membranes vary depending on membrane lipid components and their compositions, the polarization changes (\%) relative to control polarization values were used for comparing the fluidity-modifying potencies between different membranes. 


\subsection{Inhibition of Membrane Lipid Peroxidation}

The antioxidant activity was determined by the liposomal system reported previously with some modifications [21]. An aliquot $(250 \mu \mathrm{l})$ of the ethanol solution of $10 \mathrm{mM}$ total lipids and $40 \mu \mathrm{M}$ DPPP was repeatedly injected four times into $199 \mathrm{ml}$ of Dulbecco's phosphate-buffered saline of pH 7.4 (Dainippon Pharmaceuticals; Osaka, Japan) to prepare DPPP-incorporated liposomes suspended in the buffer. The lipid composition of liposomal membranes was the same as that of neuronal mimetic membranes described in Section 2.2. To the liposome suspensions of $3.97 \mathrm{ml}, 10 \mu \mathrm{l}$ of phenols and reference antioxidant $\alpha$-tocopherol solutions in DMSO were added to be final concentrations of 10 and $100 \mu \mathrm{M}$ for phenols and $1 \mu \mathrm{M}$ for $\alpha$-tocopherol, followed by incubation at $37^{\circ} \mathrm{C}$ for $30 \mathrm{~min}$. A corresponding volume $(0.25 \%$, v/v) of DMSO vehicle was added for controls. The resulting suspensions were incubated with $20 \mu \mathrm{l}$ of a peroxynitrite solution in $0.1 \mathrm{M} \mathrm{NaOH}$ to peroxidize membrane lipids with $10 \mu \mathrm{M}$ peroxynitrite. A membrane-incorporated DPPP quantitatively reacts with a lipid hydroperoxide to produce a fluorescent phosphine oxide in lipid bilayers. After the incubation at $37^{\circ} \mathrm{C}$ for $10 \mathrm{~min}$, the liposome suspensions were fluorometrically analyzed at $355 \mathrm{~nm}$ for excitation and at $382 \mathrm{~nm}$ for emission. When the peroxynitrite-induced increase of fluorescence intensity reached a plateau, the lipid peroxidation was defined as completed (100\%). The lipid peroxidation inhibitions (\%) were determined by comparing the fluorescence intensity with controls. The fluorescence intensity of liposome suspensions treated with DMSO alone was subtracted from that of liposome suspensions treated with phenols plus DMSO so that the determined effects were not affected by vehicles.

\subsection{Statistical Analysis}

All results are expressed as means \pm SEM ( $n=6$ for membrane interaction experiments and $n=5$ for lipid peroxidation experiments). Data were statistically analyzed by a one-way analysis of variance (ANOVA), followed by a post hoc Fisher's protected least significant difference (PLSD) test using StatView 5.0 (SAS Software; Cary, NC). $P$ values of 0.05 or less were regarded as statistically significant.

\section{Results}

\subsection{Effects on DPPC Membranes}

In pilot studies using DPPC model membranes, the membrane-interacting potentials of phenols and anesthetics were confirmed (Figure 2). Except for MIP and isoeugenol, phenols increased the DPPC membrane fluidity at

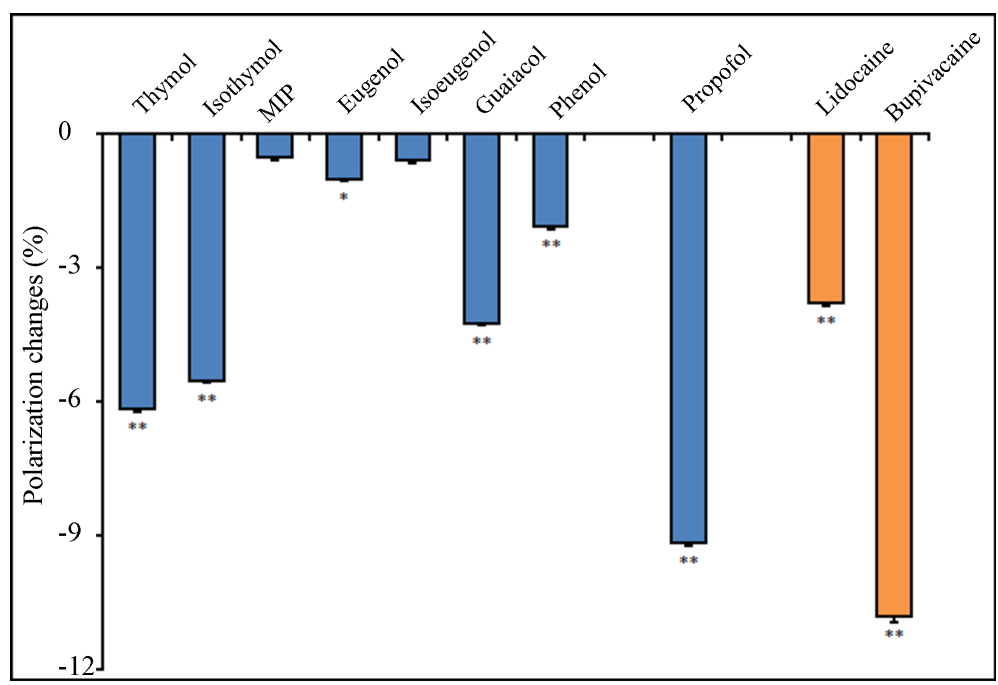

Figure 2. Effects of phenols and local anesthetics on DPPC model membranes. DPPC membranes were treated with phenols (10 $\mu \mathrm{M}$ for each) and local anesthetics (200 $\mu \mathrm{M}$ for each), followed by measuring DPH fluorescence polarization. The polarization changes (\%) relative to control values are shown as means $\pm \operatorname{SEM}(n=6) .{ }^{*} P<0.05$ and ${ }^{* *} P<0.01$ compared with control. 
$10 \mu \mathrm{M}$ as well as lidocaine and bupivacaine did at $200 \mu \mathrm{M}$. Their comparative potencies were propofol $>$ thymol $>$ isothymol $>$ guaiacol $>$ phenol $>$ eugenol, and bupivacaine > lidocaine. At concentrations higher than 200 $\mu \mathrm{M}$, alkylphenols such as propofol and thymol induced the aggregation of DPPC unilamellar vesicles as previously reported for polyphenols that aggregated phosphatidylcholine liposomes [22].

\subsection{Effects on Neuronal Mimetic Membranes}

Phenols other than isoeugenol interacted with neuronal mimetic membranes to increase their fluidity at $10 \mu \mathrm{M}$ (Figure 3). Propofol was most potent of phenols as shown by the significant DPH polarization decrease at $1 \mu \mathrm{M}$, followed by thymol, isothymol, guaiacol, phenol, eugenol and MIP. Local anesthetics also increased the fluidity of neuronal mimetic membranes at $50-200 \mu \mathrm{M}$ with the comparative potency being bupivacaine $>$ lidocaine. The membrane effects of both local anesthetics were weaker than those of membrane-interacting phenols. Compared with DPPC model membranes, the membrane fluidity decreases by phenols and local anesthetics were smaller.

\subsection{Effects on Membrane Lipid Peroxidation}

While being not as potent as antioxidant $\alpha$-tocopherol, all the tested phenols inhibited peroxynitrite-induced membrane lipid peroxidation at 10 and $100 \mu \mathrm{M}$ (Figure 4). When the lipid peroxidation inhibitions (\%) at 10 $\mu \mathrm{M}$ for each were plotted against the induced polarization changes (\%) of neuronal mimetic membranes, the linear regression analysis provided $\mathrm{y}=-0.214 \mathrm{x}-0.789, R^{2}=0.918$. The relative antioxidant activities of phenols correlated to their membrane interactivities.

\section{Discussion}

The presence of a certain amount of cholesterol in lipid bilayers decreases the fluidity of membranes [23]. Because neuronal mimetic membranes were prepared with phospholipids plus cholesterol, they are more rigid than the model membranes consisting of DPPC alone. The different membrane-fluidizing potencies of phenols and local anesthetics between neuronal mimetic and DPPC membranes are attributed to such a difference of membrane property due to lipid compositions.

Lidocaine and bupivacaine interacted with neuronal mimetic membranes at $20-200 \mu \mathrm{M}$, although their effects were not as great as phenols interacting with the same membranes at $1-10 \mu \mathrm{M}$. The relative potencies of lidocaine and bupivacaine to fluidize the membranes correlate to those of local anesthesia induced by them. A

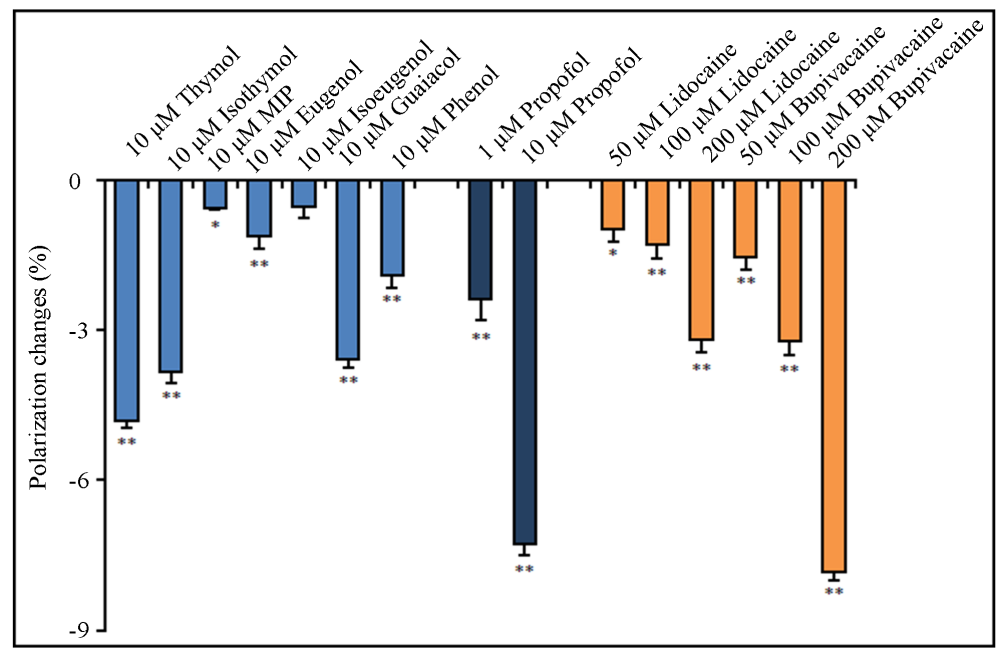

Figure 3. Effects of phenols and local anesthetics on neuronal mimetic membranes. Membranes prepared with phospholipids and cholesterol to mimic neuronal membranes were treated with phenols and local anesthetics at the indicated concentrations, followed by measuring DPH fluorescence polarization. The polarization changes (\%) relative to control values are shown as means $\pm \operatorname{SEM}(n=6) .{ }^{*} P<0.05$ and ${ }^{* *} P<0.01$ compared with control. 


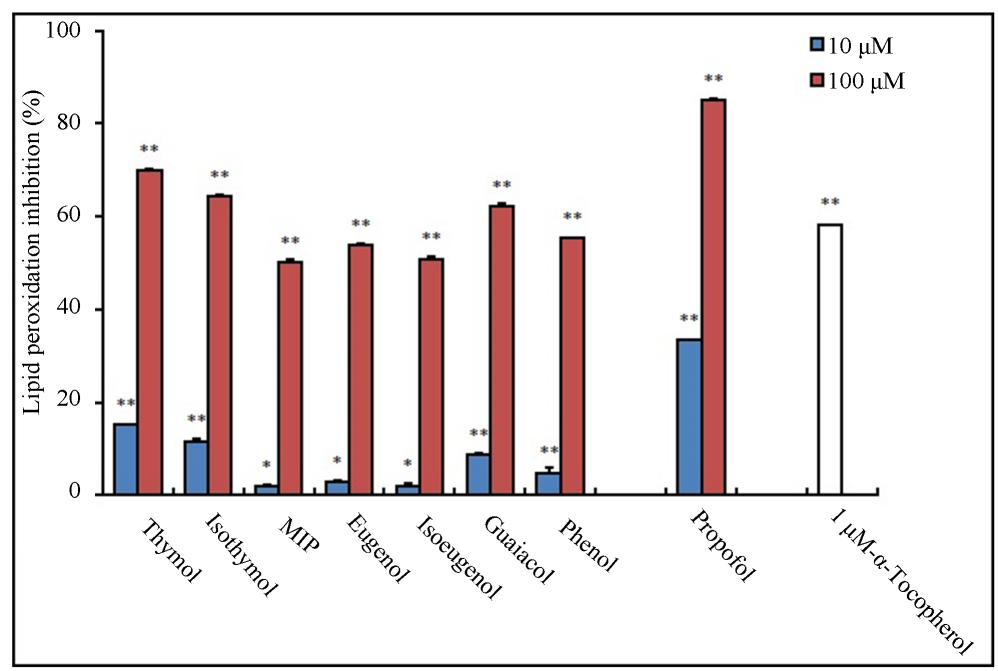

Figure 4. Effects of membrane-interacting phenols on membrane lipid peroxidation. DPPP-incorporated membranes consisting of unsaturated phospholipids and cholesterol were treated with 10 or $100 \mu \mathrm{M}$ phenols and $1 \mu \mathrm{M}$ $\alpha$-tocopherol as a reference antioxidant, and then with $10 \mu \mathrm{M}$ peroxynitrite, followed by the fluorometric analysis. The lipid peroxidation inhibitions (\%) were determined by comparing the fluorescence intensity with controls. The results are shown as means $\pm \operatorname{SEM}(n=5)$. ${ }^{*} P<0.05$ and ${ }^{* *} P<0.01$ compared with control.

relatively large volume of high concentration drugs is injected to ensure adequate local anesthesia for surgery, as $20-30 \mathrm{ml}$ of $20 \mathrm{mg} / \mathrm{ml}$ lidocaine are typically injected to block large nerves in humans [24]. Nociceptive C-fibers of rat sciatic nerves are blocked by continuously superfusing lidocaine of $0.33 \mathrm{mg} / \mathrm{ml}$ [25]. Considering clinically/experimentally-relevant and membrane-fluidizing concentrations, the membrane interaction is related to local anesthetic effects.

Even if local anesthetics are concentrated in lipid bilayers so that their intra-membrane concentrations are higher than their concentrations in the bulk aqueous phase [26], they could not achieve high micromolar concentrations in the CNS. The membrane interactions of lidocaine and bupivacaine are unlikely to contribute to the inhibition of GABA-induced currents at membrane-embedded $\mathrm{GABA}_{\mathrm{A}}$ receptors.

Thymol, eugenol and propofol penetrate into lipid bilayers to locate in the region between the polar group, the glycerol moiety and the acyl chains, with the preference of more lipophilic phenols to the deeper hydrophobic region. The structure and membrane activity relation indicated that lipophilicity and 2,6-dialkylphenol structure impart greater membrane interactivity to alkylphenols, which is consistent with previous reports [27] [28]. When comparing thymol isomers, the position of an isopropyl group is important for membrane interaction as significantly different between thymol and MIP, but not that of a methyl group as slightly different between thymol and isothymol. Additional substituents at the para-position decreases the membrane interactivity as shown by the comparisons of guaiacol, eugenol and phenol, and a 2-propenyl group is preferable to a 1-propenyl group as seen in a difference between eugenol and isoeugenol.

When orally and intravenously administered, alkylphenols show the effects on central and peripheral nerves [1] [2]. In specimens from a forensic autopsy case of a man intravenously misinjected with $500 \mathrm{mg}$ propofol, its determined concentrations were $26.8 \mathrm{ng} / \mathrm{ml}$ in blood and $129.6 \mathrm{ng} / \mathrm{g}$ in brain [29]. Higher lipophilic propofol and thymol are able to cross the blood-brain barrier and penetrate into neuronal membranes where they are concentrated. Alkylphenols concentrated in brains and nerve cells should be low micromolar levels or less, at which they could interact with membrane lipids [28] [30]. Lipid bilayer membranes mediate the effects of drugs through their induced perturbation of membrane structures, physicochemical properties or dynamics [14]. Membrane fluidity, curvature, elasticity and dipolar arrangement modulate the receptor-mediated interactions between drugs and membranes [31]. The anesthetic effects of alkylphenols are referred to as the combined results of their interactions with receptor or channel proteins and those with membrane lipids to modify the lipid environments surrounding such functional proteins [32]. 
Phenols like eugenol applied to pulp cavities achieve the concentrations in dental pulps and dentins adjacent to the pulp space to be $10-100 \mu \mathrm{M}$, but their concentrations are unlikely to be in excess of $0.1 \mathrm{mM}$ in pulp tissues [33] [34]. Dental phenols show the concentration-dependent effects: pulp-sedative at relatively low concentrations but irritant or cytotoxic at relatively high concentrations [35]. Membrane-active phenols would reversibly exert anesthetic and analgesic effects by acting on neuronal membranes at low micromolar concentrations which cover their membrane-interacting concentrations. At high micromolar or millimolar concentrations, however, they are assumed to irreversibly damage neural and pulp tissues by the lysis of lipid membranes as alkylphenols adversely acted on DPPC model membranes.

Compounds to positively modulate $\mathrm{GABA}_{\mathrm{A}}$ receptors possess the antioxidant activity, which may lead to the neuro-protection [27]. Antioxidant dugs are expected to reduce oxidative stress in the perioperative period and ischemia/reperfusion injury [36]. While the antioxidant activity of drugs has been frequently evaluated by the inhibition of lipid peroxidation, lipid samples are treated with hydroxyl, ferryl, tert-butyl hydroperoxide and 2,2diphenyl-1-picrylhydrazyl radicals in a homogenous or aqueous phase. These experimental conditions do not necessarily reflect the in vivo lipid peroxidation. Peroxynitrite produced from nitric oxide and superoxide anion plays a crucial role for the membrane lipid peroxidation in myocardial ischemia/reperfusion [37], and its peroxidation ability is modulated by the antioxidant mechanism [38]. According to the in vivo pathogenic oxidation, the antioxidant effects of phenols were determined by the phospholipid bilayer membranous system using peroxynitrite. Consequently, several phenols have been revealed to show promising effects with the rank order of lipid peroxidation inhibition being propofol $>$ thymol $>$ isothymol $>$ guaiacol $>$ phenol $>$ eugenol, consistent with that of neuronal mimetic membrane fluidization. The basic structure of phenol and substituents at the orthoposition appear to potentiate both membrane interaction and lipid peroxidation inhibition, but substituents at the para-position reduce [21] [27].

The peroxidation rate of membrane lipids depends on the propagation of oxidant and antioxidant molecules in lipid bilayers which is determined by membrane physicochemical properties such as fluidity [39]. The tested phenols are considered to interact more efficiently with radicals in more fluid lipid bilayers [40]. Their membrane-fluidizing effects are preferable to make the interaction between antioxidant molecules and radicals more efficient [41].

\section{Conclusion}

Phenols interact with the membranes consisting of unsaturated phospholipids and cholesterol to modify their fluidity with the potency correlating to anesthetic effects. The structure and membrane activity relation indicates that branched-chain alkyl groups in the ortho-position relative to a hydroxyl group increase the membrane interactivity, but additional substituents at the para-position decrease. Thymol and propofol meeting the structural requirements show the greatest membrane interaction at clinically-relevant concentrations. The structurespecific membrane interaction likely underlies the pharmacology of anesthetic phenols. Since the interaction with unsaturated phospholipid membranes could be associated with the inhibition of membrane lipid peroxidation, membrane-interacting antioxidant alkylphenols may be effective in protecting against the peroxynitriterelating ischemia/reperfusion injury.

\section{Conflict of Interest}

The authors declare there are no conflicts of interest.

\section{Acknowledgements}

This study was supported by grants-in-aid for Scientific Research 23593005 and 26463078 from the Japan Society for the Promotion of Science.

\section{References}

[1] Guenette, S.A., Beaudry, F., Marier, J.F. and Vachon, P. (2006) Pharmacokinetics and Anesthetic Activity of Eugenol in Male Sprague-Dawley Rats. Journal of Veterinary Pharmacology and Therapeutics, 29, 265-270. http://dx.doi.org/10.1111/j.1365-2885.2006.00740.X

[2] Park, S.H., Sim, Y.B., Lee, J.K., Kim, S.M., Kang, Y.J., Jung, J.S. and Suh, H.W. (2011) The Analgesic Effects and 
Mechanisms of Orally Administered Eugenol. Archives of Pharmacal Research, 34, 501-507.

http://dx.doi.org/10.1007/s12272-011-0320-z

[3] Mohammadi, B., Haeseler, G., Leuwer, M., Dengler, R., Krampfl, K. and Bufler, J. (2001) Structural Requirements of Phenol Derivatives for Direct Activation of Chloride Currents via GABA $\mathrm{A}_{\mathrm{A}}$ Receptors. European Journal of Pharmacology, 421, 85-91. http://dx.doi.org/10.1016/S0014-2999(01)01033-0

[4] García, D.A., Bujons, J., Vale, C. and Suñol, C. (2006) Allosteric Positive Interaction of Thymol with the GABA Re- $^{-}$ ceptor in Primary Cultures of Mouse Cortical Neurons. Neuropharmacology, 50, 25-35. http://dx.doi.org/10.1016/j.neuropharm.2005.07.009

[5] Haeseler, G. and Leuwer, M. (2002) Interaction of Phenol Derivatives with Ion Channels. European Journal of Anaesthesiology, 19, 1-8. http://dx.doi.org/10.1097/00003643-200201000-00001

[6] Kozek-Langenecker, S.A. (2002) The Effects of Drugs Used in Anaesthesia on Platelet Membrane Receptors and on Platelet Function. Current Drug Targets, 3, 247-258. http://dx.doi.org/10.2174/1389450023347759

[7] Pramod, K., Ansari, S.H. and Ali, J. (2010) Eugenol: A Natural Compounds with Versatile Pharmacological Actions. Natural Product Communications, 5, 1999-2006.

[8] Riella, K.R., Marinho, R.R., Santos, J.S., Pereira-Filho, R.N., Cardoso, J.C., Albuquerque-Junior, R.L. and Thomazzi, S.M. (2012) Anti-Inflammatory and Cicatrizing Activities of Thymol, a Monoterpene of the Essential Oil from Lippia gracilis, in Rodents. Journal of Ethnopharmacology, 143, 656-663. http://dx.doi.org/10.1016/j.jep.2012.07.028

[9] Bocchinfuso, G., Bobone, S., Mazzuca, C., Palleschi, A. and Stella, L. (2011) Fluorescence Spectroscopy and Molecular Dynamics Simulations in Studies on the Mechanism of Membrane Destabilization by Antimicrobial Peptides. Cellular and Molecular Life Sciences, 68, 2281-2301. http://dx.doi.org/10.1007/s00018-011-0719-1

[10] Lichtenberger, L.M., Zhou, Y., Jayaraman, V., Doyen, J.R., O’Neil, R.G., Dial, E.J., Volk, D.E., Gorenstein, D.G., Boggara, M.B. and Krishnamoorti, R. (2012) Insight into NSAID-Induced Membrane Alterations, Pathogenesis and Therapeutics: Characterization of Interaction of NSAIDs with Phosphatidylcholine. Biochimica et Biophysica Acta, 1821, 994-1002.

[11] Sheu, J.R., Hsiao, G., Luk, H.N., Chen, Y.W., Chen, T.L., Lee, L.W., Lin, C.H. and Chou, D.S. (2002) Mechanisms Involved in the Antiplatelet Activity of Midazolam in Human Platelets. Anesthesiology, 96, 651-658. http://dx.doi.org/10.1097/00000542-200203000-00022

[12] Kazanci, N. and Severcan, F. (2007) Concentration Dependent Different Action of Tamoxifen on Membrane Fluidity. Bioscience Reports, 27, 247-255. http://dx.doi.org/10.1007/s10540-007-9050-3

[13] Tsuchiya, H. (2010) Structure-Dependent Membrane Interaction of Flavonoids Associated with Their Bioactivity. Food Chemistry, 120, 1089-1096. http://dx.doi.org/10.1016/j.foodchem.2009.11.057

[14] Kopeć, W., Telenius, J. and Khandelia, H. (2013) Molecular Dynamics Simulations of the Interactions of Medicinal Plant Extracts and Drugs with Lipid Bilayer Membranes. FEBS Journal, 280, 2785-2805. http://dx.doi.org/10.1111/febs.12286

[15] Sugimoto, M., Uchida, I., Fukami, S., Takenoshita, M., Mashimo, T. and Yoshiya, I. (2000) The $\alpha$ and $\gamma$ Subunit-

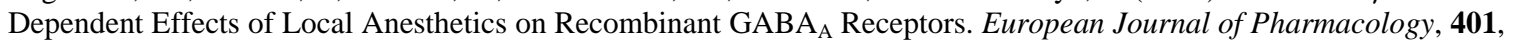
329-337. http://dx.doi.org/10.1016/S0014-2999(00)00463-5

[16] Haeseler, G., Maue, D., Grosskreutz, J., Bufler, J., Nentwig, B., Piepenbrock, S., Dengler, R. and Leuwer, M. (2002) Voltage-Dependent Block of Neuronal and Skeletal Muscle Sodium Channels by Thymol and Menthol. European Journal of Anaesthesiology, 19, 571-579. http://dx.doi.org/10.1017/S0265021502000923

[17] Park, C.K., Kim, K., Jung, S.J., Kim, M.J., Ahn, D.K., Hong, S.D., Kim, J.S. and Oh, S.B. (2009) Molecular Mechanism for Local Anesthetic Action of Eugenol in the Rat Trigeminal System. Pain, 144, 84-94. http://dx.doi.org/10.1016/j.pain.2009.03.016

[18] Lundbæk, J.A. (2006) Regulation of Membrane Protein Function by Lipid Bilayer Elasticity: A Single Molecule Technology to Measure the Bilayer Properties Experienced by an Embedded Protein. Journal of Physics: Condensed Matter, 18, S1305-S1344. http://dx.doi.org/10.1088/0953-8984/18/28/S13

[19] Søgaard, R., Werge, T.M., Bertelsen, C., Lundbye, C., Madsen, K.L., Nielsen, C.H. and Lundbæk, J.A. (2006) GABA Receptor Function Is Regulated by Lipid Bilayer Elasticity. Biochemistry, 45, 13118-13129. http://dx.doi.org/10.1021/bi060734

[20] Tsuchiya, H. and Mizogami, M. (2013) Characteristic Interactivity of Landiolol, an Ultra-Short-Acting Highly Selective $\beta_{1}$-Blocker, with Biomimetic Membranes: Comparisons with $\beta_{1}$-Selective Esmolol and Non-Selective Propranolol and Alprenolol. Frontiers in Pharmacology, 4, 150. http://dx.doi.org/10.3389/fphar.2013.00150

[21] Tsuchiya, H., Ueno, T., Tanaka, T., Matsuura, N. and Mizogami, M. (2010) Comparative Study on Determination of Antioxidant and Membrane Activities of Propofol and Its Related Compounds. European Journal of Pharmaceutical Sciences, 39, 97-102. http://dx.doi.org/10.1016/j.ejps.2009.11.001 
[22] Hendrich, A.B., Malon, R., Pola, A., Shirataki, Y., Motohashi, N. and Michalak, K. (2002) Differential Interaction of Sophora Isoflavonoids with Lipid Bilayers. European Journal of Pharmaceutical Sciences, 16, 201-208. http://dx.doi.org/10.1016/S0928-0987(02)00106-9

[23] Mainali, L., Feix, J.B., Hyde, J.S. and Subczynski, W.K. (2011) Membrane Fluidity Profiles as Deduced by Saturation-Recovery EPR Measurements of Spin-Lattice Relaxation Times of Spin Labels. Journal of Magnetic Resonance, 212, 418-425. http://dx.doi.dlorg/10.1016/j.jmr.2011.07.022

[24] Popitz-Bergez, F.A., Leeson, S., Strichartz, G.R. and Thalhammer, J.G. (1995) Relation between Functional Deficit and Intraneural Local Anesthetic during Peripheral Nerve Block. A Study in the Rat Sciatic Nerve. Anesthesiology, 83, 583-592. http://dx.doi.org/10.1097/00000542-199509000-00018

[25] Huang, J.H., Thalhammer, J.G., Raymond, S.A. and Strichartz, G.R. (1997) Susceptibility to Lidocaine of Impulses in Different Somatosensory Afferent Fibers of Rat Sciatic Nerve. Journal of Pharmacology and Experimental Therapeutics, 282, 802-811.

[26] Sinnott, C.J., Cogswell 3rd, L.P., Johnson, A. and Strichartz, G.R. (2003) On the Mechanism by Which Epinephrine Potentiates Lidocaine’s Peripheral Nerve Block. Anesthesiology, 98, 181-188. http://dx.doi.org/10.1097/00000542-200301000-00028

[27] Marín, L.D., Sánchez-Borzone, M. and García, D.A. (2011) Comparative Antioxidant Properties of Some Gabaergic Phenols and Related Compounds, Determined for Homogeneous and Membrane Systems. Medicinal Chemistry, 7, 317-324. http://dx.doi.org/10.2174/157340611796150969

[28] Tsuchiya, H. (2001) Structure-Specific Membrane-Fluidizing Effect of Propofol. Clinical and Experimental Pharmacology and Physiology, 28, 292-299. http://dx.doi.org/10.1046/j.1440-1681.2001.03441.x

[29] Hikiji, W., Kudo, K., Usumoto, Y., Tsuji, A. and Ikeda, N. (2010) A Simple and Sensitive Method for the Determination of Propofol in Human Solid Tissues by Gas Chromatography-Mass Spectrometry. Journal of Analytical Toxicology, 34, 389-393. http://dx.doi.org/10.1093/jat/34.7.389

[30] Bahri, M.A., Seret, A., Hans, P., Piette, J., Deby-Dupont, G. and Hoebeke, M. (2007) Does Propofol Alter Membrane Fluidity at Clinically Relevant Concentrations? An ESR Spin Label Study. Biophysical Chemistry, 129, 82-91. http://dx.doi.org/10.1016/j.bpc.2007.05.011

[31] Sánchez, M.E., Turina, A.V., Garćia, D.A., Nolan, M.V. and Perillo, M.A. (2004) Surface Activity of Thymol: Implications for an Eventual Pharmacological Activity. Colloids and Surfaces B: Biointerfaces, 34, 77-86.

http://dx.doi.org/10.1016/j.colsurfb.2003.11.007

[32] Reiner, G.N., Fraceto, L.F., de Paula, E., Perillo, M.A. and García, D.A. (2013) Effects of Gabaergic Phenols on Phospholipid Bilayers as Evaluated by ${ }^{1} \mathrm{H}-\mathrm{NMR}$. Journal of Biomaterials and Nanotechnology, 4, 28-34. http://dx.doi.org/10.4236/jbnb.2013.43A004

[33] Hume, W.R. (1984) An Analysis of the Release and the Diffusion through Dentin of Eugenol from Zinc Oxide-Eugenol Mixtures. Journal of Dental Research, 63, 881-884. http://dx.doi.org/10.1177/00220345840630061301

[34] Hashimoto, S., Uchiyama, K., Maeda, M., Ishitsuka, K., Furumoto, K. and Nakamura, Y. (1988) In Vivo and in Vitro Effects of Zinc Oxide-Eugenol (ZOE) on Biosynthesis of Cyclooxygenase Products in Rat Dental Pulp. Journal of Dental Research, 67, 1092-1096. http://dx.doi.org/10.1177/00220345880670080601

[35] Markowitz, K., Moynihan, M., Liu, M. and Kim, S. (1992) Biologic Properties of Eugenol and Zinc Oxide-Eugenol: A Clinically Oriented Review. Oral Surgery, Oral Medicine, Oral Pathology, 73, 729-737. http://dx.doi.org/10.1016/0030-4220(92)90020-Q

[36] Ross, S. and Foëx, P. (1999) Protective Effects of Anaesthetics in Reversible and Irreversible Ischaemia-Reperfusion Injury. British Journal of Anaesthesia, 82, 622-632. http://dx.doi.org/10.1093/bja/82.4.622

[37] Lalu, M.M., Wang, W. and Schulz, R. (2002) Peroxynitrite in Myocardial Ischemia-Reperfusion Injury. Heart Failure Reviews, 7, 359-369. http://dx.doi.org/10.1023/a:1020766502316

[38] Radi, R. (2013) Peroxynitrite, a Stealthy Biological Oxidant. Journal of Biological Chemistry, 288, $26464-26472$. http://dx.doi.org/10.1074/jbc.R113.472936

[39] Suzuki, Y.J., Tsuchiya, M., Wassall, S.R., Choo, Y.M., Govil, G., Kagan, V.E. and Packer, L. (1993) Structural and Dynamic Membrane Properties of $\alpha$-Tocopherol and $\alpha$-Tocotrienol: Implication to the Molecular Mechanism of Their Antioxidant Potency. Biochemistry, 32, 10692-10699. http://dx.doi.org/10.1021/bi00091a020

[40] Lúcio, M., Ferreira, H., Lima, J.L. and Reis, S. (2007) Use of Liposomes to Evaluate the Role of Membrane Interactions on Antioxidant Activity. Analytica Chimica Acta, 597, 163-170. http://dx.doi.org/10.1016/j.aca.2007.06.039

[41] Gutiérrez, M.E., García, A.F., Africa de Madariaga, M., Sagrista, M.L., Casadó, F.J. and Mora, M. (2003) Interaction of Tocopherols and Phenolic Compounds with Membrane Lipid Components: Evaluation of Their Antioxidant Activity in a Liposomal Model System. Life Sciences, 72, 2337-2360. http://dx.doi.org/10.1016/s0024-3205(03)00120-6 


\author{
Abbreviation List \\ 3-Methyl-4-isopropylphenol (MIP); \\ 1,2-Dipalmitoylphosphatidylcholine (DPPC); \\ 1-Palmitoyl-2-oleoylphosphatidylcholine (POPC); \\ 1-Palmitoyl-2-oleoylphosphatidylethanolamine (POPE); \\ 1-Palmitoyl-2-oleoylphosphatidylserine (POPS); \\ Sphingomyelin (SM); \\ 1,6-Diphenyl-1,3,5-hexatriene (DPH); \\ Diphenyl-1-pyrenylphosphine (DPPP); \\ Dimethyl sulfoxide (DMSO).
}


Scientific Research Publishing (SCIRP) is one of the largest Open Access journal publishers. It is currently publishing more than 200 open access, online, peer-reviewed journals covering a wide range of academic disciplines. SCIRP serves the worldwide academic communities and contributes to the progress and application of science with its publication.

Other selected journals from SCIRP are listed as below. Submit your manuscript to us via either submit@scirp.org or Online Submission Portal.
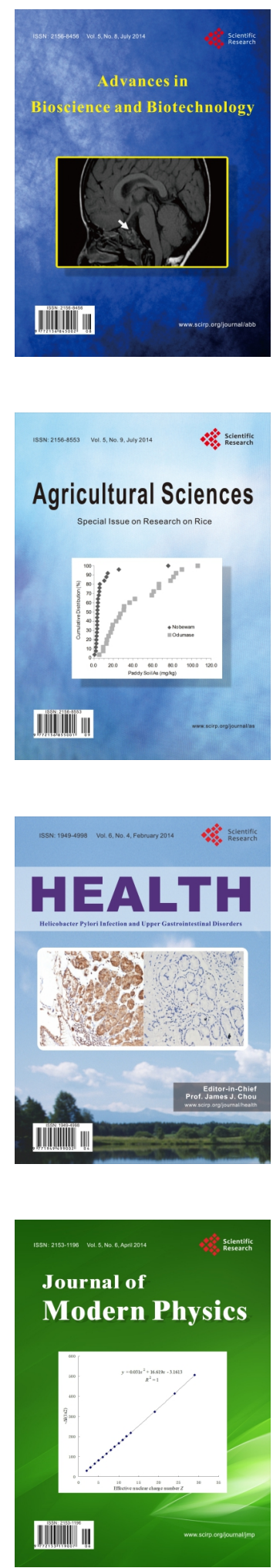
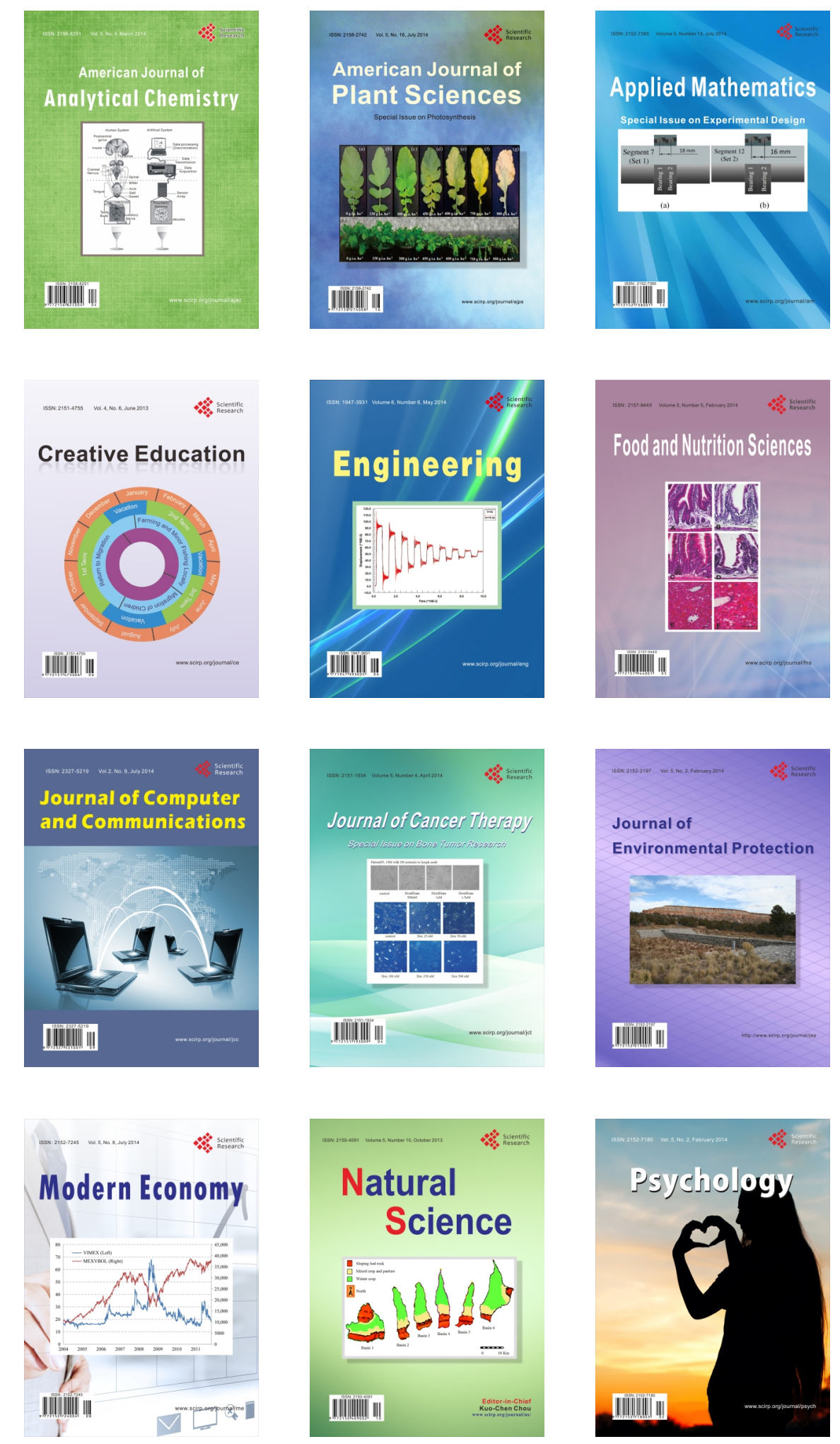